\title{
The risk of cardiovascular events in persons with a non-cardiac pathology
}

\author{
Olga Khlynova ${ }^{a}$, Alexander Tuev ${ }^{\mathrm{a}}$, Liubov Vasilets ${ }^{\mathrm{a}}$, Ekaterina Shishkina $^{\mathrm{b}}$, Sergey Naumov ${ }^{\mathrm{b}}$, Grigoriy Spasenkov $^{\mathrm{b}}$, \\ Tatiana Kalashnikova ${ }^{a}$ \\ ${ }^{\text {a} P e r m ~ S t a t e ~ M e d i c a l ~ U n i v e r s i t y ~ n a m e d ~ a f t e r ~ A c a d e m i c i a n ~ E . ~ A . ~ W a g n e r, ~} 614990$ Perm, Russian Federation. \\ bState Budgetary Healthcare Establishment of Perm Region "Cardiological Clinic", 614002 Perm, Russian Federation.
}

\begin{tabular}{|c|c|}
\hline ARTICLE INFO & ABSTRACT \\
\hline $\begin{array}{l}\text { Article history: } \\
\text { Received on: } 07 / 04 / 2017 \\
\text { Accepted on: } 20 / 06 / 2017 \\
\text { Available online: } 30 / 07 / 2017\end{array}$ & $\begin{array}{l}\text { Nowadays, one of the main areas in internal disease treatment is preventive medicine, which includes the risk } \\
\text { measurement method. This method is often used in cardiology to assess both the chances of a disease's } \\
\text { emergence and its progression or complicated course. The purpose of this study was to investigate the } \\
\text { possibilities of identifying factors of cardiovascular risks in people with gastroesophageal reflux disease and } \\
\text { obesity Eighty patients. }\end{array}$ \\
\hline $\begin{array}{l}\text { Key words: } \\
\text { Cardiovascular disease } \\
\text { model, chronobiologic } \\
\text { indicators, discriminant } \\
\text { analysis method, } \\
\text { gastroesophageal reflux } \\
\text { disease, obesity. }\end{array}$ & $\begin{array}{l}\text { distinguishing prognostic factors of cardiovascular risks for persons with isolated forms of gastroesophageal } \\
\text { reflux disease and obesity, as well as their comorbidity. The developed formulas and models allow assessing the } \\
\text { risk of cardiovascular diseases individually for obesity, gastroesophageal reflux disease, and the combination } \\
\text { thereof. We determined the risk of cardiovascular diseases in obese people and gastroesophageal reflux disease } \\
\text { patients, which results from the features of the chronobiologic indicators of the organism, the metabolic profile, } \\
\text { and the degree of deleterious lesions of the esophageal mucosa in patients. The presented model characterizes } \\
\text { the probability of emergence of cardiovascular diseases in patients with non-cardiac pathologies. This study can } \\
\text { be used to design new methods for preventing cardiovascular events. }\end{array}$ \\
\hline
\end{tabular}

\section{INTRODUCTION}

The incidence of gastroesophageal reflux disease and obesity has been on the rise all over the world over the past several decades (Camilleri, 2005; Nandurkar, 2006; Kachina, 2013). Despite the fact that several studies have been devoted to investigating the possibility of their comorbidity, the understanding of the mechanisms behind it is far from full (Farup et al., 2001; Jones, 2005; Anand and Katz, 2010). When studying the association of gastroesophageal reflux disease and obesity, it is necessary to take into consideration the fact that both diseases develop in persons that have problems with nutrition and lifestyle, as well as a genetic predisposition to such diseases (Jones, 2005; Tkach, 2007).

\footnotetext{
* Corresponding Author

Email: olgaakhlynovaa @ gmail.com
}

In addition, it has been proven that patients with combined gastroesophageal reflux disease and obesity often have apnea episodes in their sleep, systemic inflammation associated with obesity, which emerges when the level of circulating cytokines (interleukin-6, tumor necrosis factor alpha) increases, oxidative stress, and hormone secretion disorders (leptin, adiponectin, resistin), which exacerbate the pathogenic mechanisms of formation and progression of both gastroesophageal reflux disease and obesity (Camilleri, 2005; Khlynova, 2012; Vasilets, 2014). These factors can also increase the risk of cardiovascular diseases in persons with an associated course of gastroesophageal reflux disease and obesity. Various studies have confirmed the existence of a certain correlation between the exacerbation of gastroesophageal reflux disease and body weight gain in humans. These studies have also noted that an increase in alcohol consumption and smoking abuse could cause obesity (Hampel et al., 2005). 
This study aims to investigate the possibilities of emergence of cardiovascular risk factors in gastroesophageal reflux disease and obesity patients and to develop models with characteristics that could serve as a background for the development of gastroesophageal reflux disease.

\section{MATERIALS AND METHODS}

This was a simple open one-stage comparative study that included 80 patients: 56 men (70\%) and 24 women (30\%) (average age was $47.1 \pm 5.5)$. Forty patients with gastroesophageal reflux disease constituted the main observation group, while theother 40 patients constituted the comparison group - without gastroesophageal reflux disease, but with varying body weight (excess body weight and obesity). All patients underwent general clinical examinations. The metabolic status of patients (Bartz et al., 2014), the presence of helicobacter infection (Uotaniand Graham, 2014), and the levels of adiponectin and C-reactive protein (Wium-Andersen et al., 2013) were tested separately. If signs of gastroesophageal reflux disease were discovered based on the data of the questionnaire, such patients underwent esophagogastroduodenoscopy (Lieberman et al., 1985), with a view to determining the clinical-endoscopic variant of the gastroesophageal reflux disease and detecting complications thereof. Combined daily monitoring of patients with a Kardiotehnika-04-AD monitoring device (Inkart, Saint Petersburg) was conducted, with a view to analyzing the heart rate variability (HRV) and studying the chronobiologic characteristics of blood pressure.

The statistical analysis of obtained data was conducted using STATISTICA 6.0 software. In order to assess the interaction between the quantitative attributes, a correlation analysis was conducted, which involved the calculation of Spearman's rank correlation coefficient $(\mathrm{R})$ at $\mathrm{p}<0.05$ significance level. In addition to the correlation analysis, a multifactorial analysis of variance was conducted when rejecting the null hypothesis, with a view to constructing the moduli of patients in the context of interaction of various factors. Discriminant analysis (Fraley and Raftery, 2002) was used to study the possibility of predicting cardiovascular risks. This analysis distinguishes the quantitative attributes of classification categories and allows calculating the prognostic score of significance for the values under consideration (Wilkslambda, atp<0.05).

\section{RESULTS}

A comprehensive conclusion regarding the patients with gastroesophageal reflux disease, obesity, and combination thereof was based on the clinical and anamnestic analysis, results of laboratory studies on the metabolic profile of patients, and the discovered characteristics of chronobiologic indicators of the cardiovascular system. The study determined the levels of various indicators in case of gastroesophageal reflux disease, at which cardiovascular diseases can develop. The analysis of variance and discriminant analysis involved the creation of models of patients with certain risk factors of cardiovascular events, the significance whereof differed based on the nosological form of the disease (Figures 1, 2, 3).

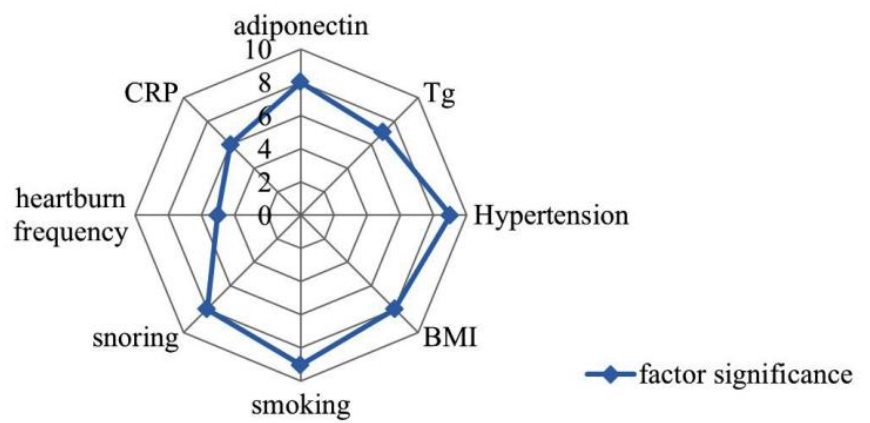

Fig. 1: Model of a patient with GERD with risk factors of cardiovascular events

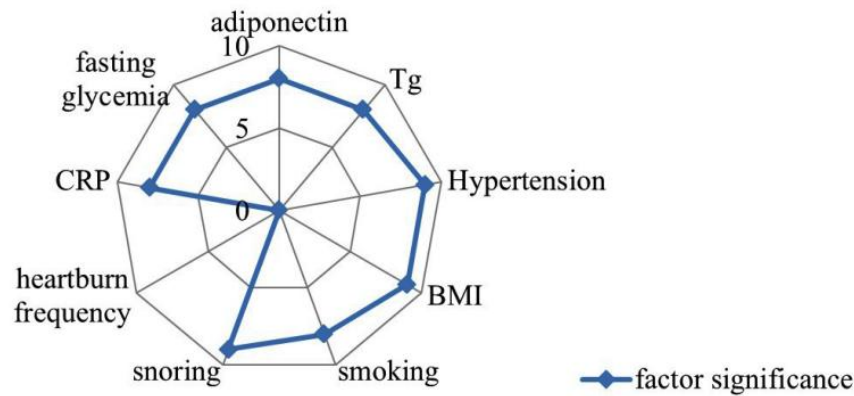

Fig. 2: Model of a patient with obesity and risk factors of cardiovascular events

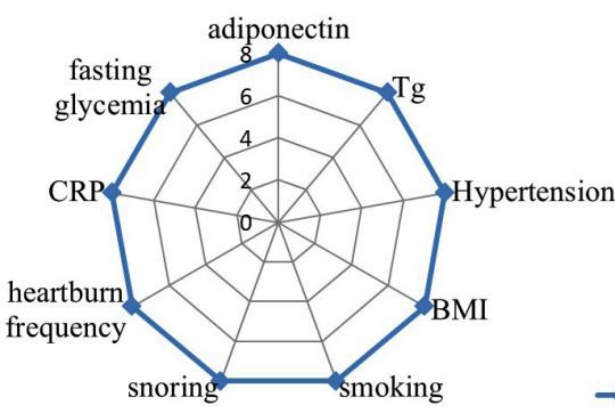
cardiovascular events

After examining the models of patients with gastroesophageal reflux disease and a risk of cardiovascular events and models of patients with obesity and the same risk, we combined them to create a new model. It incorporated the attributes that were typical for both gastroesophageal reflux disease and obesity and demonstrated the significance of factors that affected the development of the diseases.

In order to objectize the cardiovascular risk in patients with gastroesophageal reflux disease and/or obesity, we additionally created mathematical prognostic formulas, where the probability of cardiovascular events was the highest at $p$ $($ prognostic score $)>5$. 
For Gastroesophageal Reflux Disease (GERD):

$$
\mathrm{p} \quad=\quad 0.45 \times \mathrm{RE}+0.8 \times \mathrm{MSLSBP}-
$$

0.41 xadiponectin+0.97xBMI+0.25xHF+0.94xVARSBP (in sleep)

For obesity:

$\mathrm{p}=0.15 \mathrm{xfastingglycaemia}-0.68 \mathrm{xadiponectin}+0.94 \mathrm{xBMI}$

$+0.55 \mathrm{xCRP}+0.98 \mathrm{xLF}+0.24 \mathrm{xMSRDBP}+0.041 \mathrm{xVARDBP}$ (atday)

$+0.094 \mathrm{xCHOLLDP}$

For combined GERD (gastroesophageal reflux disease) and obesity:

$\mathrm{p}=0.24 \mathrm{xRE}+0.09 \times \mathrm{xBM}-0.64 \mathrm{xadiponectin}+$ $0.01 \times$ fastingglycaemia $+0.013 \times$ CHOLLDP $+0.01 \times A O+$ 0.1 xsmoking,

where RE means reflux esophagitis, MSL and MSR means the level and rate of the morning surge in blood pressure, BMI means body mass index, VAR means blood pressure variability, HF means high-frequency waves, LF mean slow-frequency waves, CRP means C-reactive protein, AO means abdominal obesity.

\section{DISCUSSION}

As other researchers have proven, considerable body weight gain and reduced physical activity increases the risk of cardiovascular diseases, type 2 diabetes, and even colon and breast cancer. Extraregular physical training can help lower these risks. It can also be a good preventive measure against diseases (Voulgari et al., 2011).

A recent study compared the risk of heart failure in obese people with without a metabolic syndrome and that in normal people with a metabolic syndrome. The study showed that the body mass index was unrelated to the development of heart failure. People with a normal body type and subcutaneous fat level but with a metabolic syndrome had a higher probability of heart failure than people with obesity did (Voulgari et al., 2011).

As an example of the implementation of our model, consider a case of a 43-year-old American, who had evident problems with the cardiovascular system in the setting of obesity, apnea in his sleep, and gastroesophageal reflux disease. He had an increased risk of myocardial infarction; he was also found to have atherosclerosis. His difficult condition included the risk of heath failure, which is why he had to undergo several surgeries (Apovian and Gokce, 2012). This case shows how difficult the consequences of such a dangerous combination of gastroesophageal reflux disease and obesity can be for the organism and why it is important to develop methods for the prevention of cardiovascular diseases.

Previous studies on the gastroesophageal reflux disease discovered that it could be accompanied by obesity, increase in body mass index, and metabolic syndrome. All of the above are risk factors of cardiovascular disease development, which is why it is necessary to pay special attention to monitoring the state of the cardiovascular system in patients in such a state (Goh, 2011). Obesity was proven to be associated with an increased risk of esophageal diseases, including adenocarcinoma.
These changes are more typical for men; such diseases often develop in the setting of obesity. It addition, they can cause gastroesophageal reflux disease or exacerbate it significantly (Lagergren, 2011). Other researchers proved that body weight loss could reduce the intensity of the gastroesophageal disease, which had an indirect positive effect on the prevention of cardiovascular diseases (Singh et al., 2013).

The risk of obesity related cardiovascular diseases could be prevented via existing methods that determine the adipose tissue content and monitor the endocrine profile of patients (Wang and Nakayama, 2010). By using the herein developed model, it is possible to figure out if the patient is part of a risk group and, by combining existing methods, have him or her undergo additional examinations, with a view to confirming the diagnosis and determining possible accompanying diseases.

We plan to improve the model to make it incorporate more factors that can cause cardiovascular diseases. For instance, we plan to investigate cardiovascular diseases in the setting of chronic liver disease (Herzog et al., 2011) and other diseases that can have a negative impact on the patients' health.

The obtained results can be used to develop various methods for the prevention of cardiovascular diseases, obesity, and GERD.

\section{CONCLUSION}

1. Patients with gastroesophageal reflux disease and obesity are at risk of cardiovascular events, caused by the characteristics of their cardiovascular system chronobiologic indicators, metabolic profile, and the degree of deleterious lesions of the esophageal mucosa in case of gastroesophageal reflux disease.

2. The study presented a model of patients with a noncardiac pathology with the probability of cardiovascular events, the prognostic score whereof can be calculated by using classification formulas.

3. The combination of gastroesophageal reflux disease and obesity increases the number of factors that affect the development of cardiovascular diseases.

4. The study again proved the negative impact of obesity on the cardiovascular system.

The results of the study can be used to create methods for preventing cardiovascular diseases and to formulate recommendations for doctors, which will help them to detect such diseases at earlier stages.

Our plan is to improve the model and expand the range of possible factors of cardiovascular pathologies with non-cardiac diseases.

\section{Financial support and sponsorship: Nil.}

Conflict of Interests: There are no conflicts of interest. 


\section{REFERENCES}

Anand G, Katz PO. Gastroesophageal reflux disease and obesity. GastroenterolClin N, 2010; 39: 39-46.

Apovian CM, Gokce N. Obesity and cardiovascular disease. Circulation, 2012; 125: 1178-1182.

Bartz S, Mody A, HornikCh, Bain J, Muehlbauer M, Kiyimba T, Kiboneka E, Stevens R, Bartlett J, St Peter J, NewgardCh, Freemark M. Severe acute malnutrition in childhood: hormonal and metabolic status at presentation, response to treatment, and predictors of mortality. J ClinEndocrMetab, 2014; 99: 2128-2137.

Camilleri M.Prevalence and socioeconomic impact of functional gastrointestinal disorders in the United States: results from the US Upper Gastrointestinal Study. ClinGastroenterolHepatol, 2005; 3: 543 552

Farup C, Kleinman L, Sloan Sh, Ganoczy D, Chee E, Lee C, Revicki D. The impact of nocturnal symptoms associated with gastroesophageal reflux disease on health-related quality of life. ArchIntern Med, 2001; 161: 45-52.

Fraley C, Raftery AE. Model-based clustering, discriminant analysis, and density estimation. J Am Stat Assoc, 2002;97: 611-631.

Goh KL. Gastroesophageal reflux disease in Asia: A historical perspective and present challenges. JGastroenHepatol, 2011; 26: 2-10.

Hampel H, Abraham NS, El-Serag HB. Meta-analysis: obesity and the risk for gastroesophageal reflux disease and its complications. AnnInt Med, 2005; 143: 199-211.

Herzog CA, Asinger RW, Berger AK, Charytan DM, Diez J, Hart RG, Eckardt K-U, Kasiske BL, McCullough PA, Passman RS, DeLoach SS, Pun PH, Ritz E.Cardiovascular disease in chronic kidney disease. A clinical update from Kidney Disease: Improving Global Outcomes (KDIGO). Kidney Int, 2011; 80: 572-586.

IsmailovaKhZ. Comparative assessment of the clinical and functional state of the upper gastrointestinal tract in patients with GERD and hypertention combined with GERD. JN MedTech, 2016; 23: 112-118.

Jones RH.Gastroesophageal reflux disease in primary care in Europe: clinical presentation and endoscopic findings. Eur J Gen Pract, 2005; 1: 149-154.

KachinaAA. Gastroesophageal reflux disease and obesity: quality of life peculiarities. Perm Med J, 2013; 2: 20-26.

Khlynova OV. What dangers do the diseases of civilization hold for the cardiovascular system? Ural Branch of the Russian Academy of Medical Sciences Perm Research Center Journal, 2012; 3-4: 4-10.
Lagergren J. Influence of obesity on the risk of esophageal disorders. Nat Rev Gastro Hepat, 2011; 8: 340-347.

Lieberman DA, Wuerker CK, Katon RM. Cardiopulmonary risk of esophagogastroduodenoscopy: role of endoscope diameter and systemic sedation. Gastroenterology, 1985; 88: 468-472.

Nandurkar S.Epidemiology and natural history of reflux disease. Baillieres Best Pract Res ClinGastroenterol,2006; 5: 743-757.

Singh M, Lee J, Gupta N, Gaddam S, Smith BK, Wani SB, Sullivan DK, Rastogi A, Bansal A, Donnely J, Sharma P. Weight loss can lead to resolution of gastroesophageal reflux disease symptoms: a prospective intervention trial. Obesity, 2013; 21: 284-290.

Tkach SM. Gastroenterological consequences of excess body weight and obesity. Health of Ukraine, 2007; 20/1: 54-55.

Uotani T, Graham DY. Diagnosis of Helicobacter pylori using the rapid urease test. AnnTransl Med, 2014; 3.

Vasilets LM.Ventricular preexcitation syndromes: diagnostic significance of serum markers of fibrosis and inflammation. CardiovascTherPrev,2014;3: 22-22a.

Voulgari C, Tentolouris N, Dilaveris P, Tousoulis D, Katsilamboros, Stefanadis Ch. Increased heart failure risk in normalweight people with metabolic syndrome compared with metabolically healthy obese individuals. J AmCollCardiol, 2011; 58: 1343-1350.

Wang Z, Nakayama T. Inflammation, a link between obesity and cardiovascular disease. MediaInflamm, 2010.

Wium-Andersen MK, Nielsen SF, Orsted DD, Nordestgaard BG, Elevated C-Reactive Protein Levels, Psychological Distress, and Depression in 73á131 Individuals. JAMA Psychiatry, 2013; 70: 176-184.

\section{How to cite this article:}

Khlynova O, Tuev A, Vasilets L, Shishkina E, Naumov S, Spasenkov G, Kalashnikova T. The risk of cardiovascular events in persons with a non-cardiac pathology. J App Pharm Sci, 2017; 7 (07): 208-211. 